Aisyah Journal of Informatics and Electrical Engineering

Universitas Aisyah Pringsewu

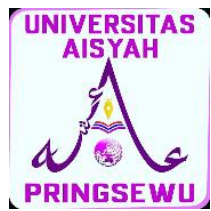

Journal Homepage

http://jti.aisyahuniversity.ac.id/index.php/AJIEE

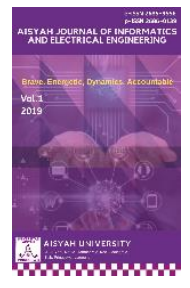

\title{
SISTEM PENDUKUNG KEPUTUSAN PENENTUAN DOSEN TELADAN \\ MENGGUNAKAN LOGIKA FUZZY MAMDANI DAN ELIMINATION AND CHOICE EXPRESSING REALITY (Studi Kasus: STMIK Surya Intan Kotabumi)
}

\author{
Herni Dwi Madona \\ Teknik Informatika, Informatics and Business Institute (IIB) Darmajaya \\ Jl. Z.A. Pagar Alam No.93 Gedong Meneng, Bandar Lampung \\ e-mail : hernidwimadona@gmail.com
}

\begin{abstract}
Lecturers are professional educators and scientists with the main task of transforming, developing and disseminating Science and Technology through Education, Research and Community Service. Lecturers have functions, roles and strategic positions in national development in the field of education, especially universities. As one of the private universities STMIK Surya Intan Kotabumi always tries to improve the quality of lecturers by providing training by inviting speakers and / or sending lecturers in events organized by Kopertis or by professional groups and given the opportunity to continue their studies. The research will determine an exemplary lecturer based on intelligent computing systems using Fuzzy Mamdani and a decision support system will be built using the multic Criteria decision making analysis method, namely Electre. The calculation will produce the final value after the final value is obtained, the next step is to compare between the two methods using MSE (Mean Squared Error). By using Fuzzy Mamdani logic and Elimination and Choice Expressing Reality (ELECTRE) and MSE (Mean Squared Error) methods can produce accurate values in decision making to determine the model lecturer at STMIK Surya Intan Kotabumi.
\end{abstract}

Keywords: Decision Support System, Model Lecturer, Fuzzy Mamdani , Electre Method

\begin{abstract}
ABSTRAK
Dosen adalah pendidik profesional dan ilmuwan dengan tugas utama mentransformasikan, mengembangkan dan menyebarluaskan Ilmu Pengetahuan dan Teknologi melalui Pendidikan, Penelitian dan Pengabdian kepada Masyarakat. Dosen mempunyai fungsi, peran dan kedudukan yang strategis dalam pembangunan nasional dibidang pendidikan khususnya perguruan tinggi. Sebagai salah satu perguruan tinggi swasta STMIK Surya Intan Kotabumi selalu berusaha meningkatkan mutu dosen dengan cara memberikan pelatihan-pelatihan dengan mendatangkan narasumber dan atau mengirim dosen dalam acara-acara yang diselenggarakan oleh kopertis atau oleh kelompok profesi serta diberikan
\end{abstract}


kesempatan untuk lanjut studi. Penelitian akan menentukan dosen teladan yang berbasis sistem komputasi cerdas menggunakan Fuzzy Mamdani serta akan dibangun sistem pendukung keputusan dengan menggunakan metode analisis pengambilan keputusan multikriteria yaitu Electre. Perhitungan akan menghasilkan nilai akhir selanjutnya setelah nilai akhir didapat maka tahap berikutnya membandingkan antara kedua metode dengan menggunakan MSE (Mean Squared Error). Dengan menggunakan logika Fuzzy Mamdani dan metode Elimination and Choice Expressing Reality (ELECTRE) serta MSE (Mean Squared Error) dapat menghasilkan nilai yang akurat dalam pengambilan keputusan untuk menentukan dosen teladan pada STMIK Surya Intan Kotabumi.

Kata Kunci : Sistem Pendukung Keputusan, Dosen Teladan, Fuzzy Mamdani, Electre 


\section{PENDAhUluan}

Dosen adalah pendidik profesional dan ilmuwan dengan tugas utama mentransformasikan, mengembangkan dan menyebarluaskan Ilmu Pengetahuan dan Teknologi melalui Pendidikan, Penelitian dan Pengabdian kepada Masyarakat. Dosen mempunyai fungsi, peran dan kedudukan yang strategis dalam pembangunan nasional dibidang pendidikan khususnya perguruan tinggi. STMIK Surya Intan Kotabumi Lampung Utara memiliki dosen dengan jumlah 30 orang dimana proses penilaian kinerja setiap dosennya dilaksanakan setiap tahun yaitu akhir semester genap. Sebagai salah satu perguruan tinggi swasta STMIK Surya Intan Kotabumi selalu berusaha meningkatkan mutu dosen dengan cara memberikan pelatihan-pelatihan dengan mendatangkan narasumber dan atau mengirim dosen dalam acara-acara yang diselenggarakan oleh kopertis atau oleh kelompok profesi serta diberikan kesempatan untuk lanjut studi. Proses penilaian yang dilakukan meliputi penilaian dosen oleh mahasiswa dengan kriteria penilaian waktu mengajar, kerapihan berpakaian, komunikasi, proses perkuliahan, penguasaan materi dan evaluasi belajar. Penelitian akan menentukan dosen teladan yang berbasis sistem komputasi cerdas menggunakan Fuzzy Mamdani serta metode analisis pengambilan keputusan multikriteria yaitu Electre. Perhitungan menggunakan Logika Fuzzy Mamdani dan Elimination and Choice Expressing Reality (ELECTRE) akan menghasilkan nilai akhir selanjutnya setelah nilai akhir didapat maka tahap berikutnya membandingkan antara kedua metode dengan menggunakan MSE (Mean Squared Error). MSE akan membantu menentukan metode mana yang paling optimal untuk digunakan sehingga dapat membantu dalam pembuatan sistem pengambilan keputusan dimana pengambilan sebuah keputusan dapat dilakukan secara lebih cepat dan tepat, sesuai dengan variabel yang diinginkan atau setidaknya mendekati variabel yang diinginkan.

Tesis ini adalah asli dan bukan plagiat sebagian atau keseluruhan serta belum pernah diajukan untuk mendapatkan gelar akademik dimanapun. Karya tulis ini adalah murni gagasan, rumusan dan penelitian saya sendiri melalui proses pembimbingan dan pengujian. Semua kutipan petikan dan saduran dari karya orang lain saya tuliskan namanya dengan jelas serta saya cantumkan dalam daftar pustaka. Pernyataan ini saya buat dengan sebenar-benarnya.

\section{TINJAUAN PUSTAKA}

Adapun kerangka penelitian ini adalah sebagai berikut:

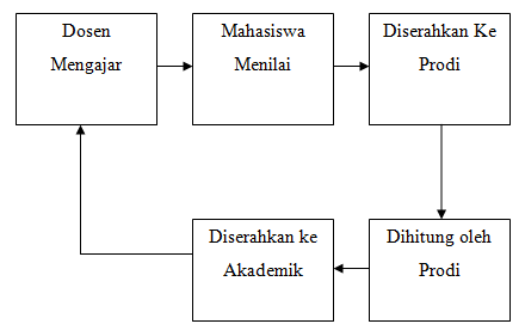

Gambar 1. Bagan Kerangka

Langkah awal yang harus dinilai yaitu dalam hal menyampaikan atau dalam proses belajar mengajar selanjutnya nilai yang telah diberikan mahasiswa dikumpulkan ke program studi setelah dikumpulkan di program studi maka dihitung dan ditotal nilainya selanjutnya hasil perhitungan diserahkan ke akademik untuk di bahas. Selanjutnya jika ada dosen yang sekiranya nilainya dibawah standar maka pihak akademik yang secara langsung memanggil dosen tersebut untuk 
dilakukan sharing dan untuk dosen yang nilainya standar akan dilakukan bimbingan dan peningkatan kemudian dosen dengan nilai tertinggi akan diberikan penghargaan serta sebagai contoh bagi dosen yang lain. (Rohmat, 2015)

\section{METODOLOGI}

Jenis penelitian ini yaitu penelitian yang dipergunakan untuk memecahkan masalah yang ada disuatu tempat misalnya organisasi, instansi, perusahaan. Penelitian terapan dilakukan untuk menjawab pertanyaan tentang permasalahan yang khusus atau untuk membuat keputusan tentang suatu tindakan atau kebijakan khusus. (Sujarweni, 2014)

\section{A. Perhitungan Metode Fuzzy Mamdani}

Sebelum masuk keperhitungan dengan menggunakan metode fuzzy mamdani maka akan ditentukan beberapa hal sebagai berikut :

Agar memudahkan dalam perhitungan dengan metode fuzzy mamdani maka akan dibuat nama dosen disebut Alternatif dan dilambangkan dengan A1 sampai dengan A30 dapat dilihat pada tabel berikut :

Tabel 3.1. Data Dosen Untuk Perhitungan

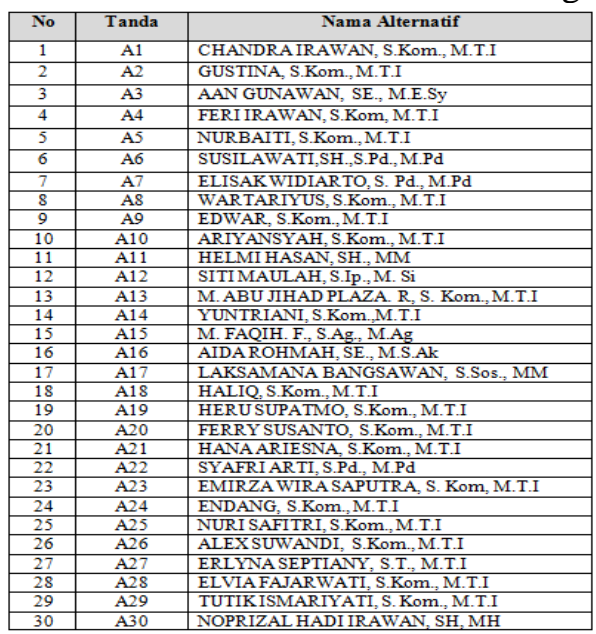

A. Perhitungan Metode Electre

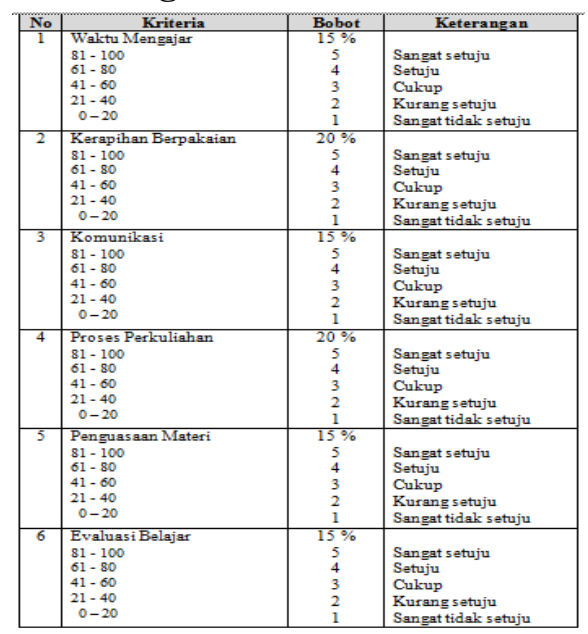

B. Perhitungan Metode Electre

Tabel 3.3 Kriteria dan Bobot Electre

[R1] IF waktu mengajar_ tinggi AND kerapihan berpakaian_rendah AND komunikasi_ tinggi AND proses perkuliahan_rendah AND penguasaan materi_ tinggi AND evaluasi belajar_tinggi

$a$ - predikat $_{1}$ $=$ $(0,15 * 5,67+0,20 * 4,25+0,15 * 5,67+0$, $20 * 4,25+$

$0,15 * 5,67+0,15 * 5,67)=5.1$

\section{$z_{1}=\mathbf{5 . 1}$}

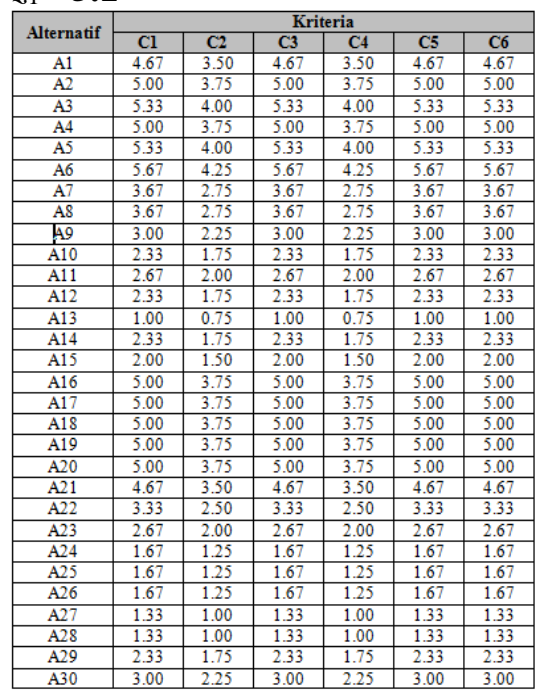

IV. HASIL DAN PEMBAHASAN

Aisyah Journal of Informatics and Electrical Engineering 
Berdasarkan data hasil penelitian diatas maka penulis melakukan perhitungan dan pembuktian normalitas dan uji persyaratan apakah data yang didapatkan benar-benar berdistribusi normal dan memiliki akurasi antara kedua metode yang digunakan. Berikut ini hasil rekap kuesioner penentuan dosen teladan yang akan digunakan sebagai data dasar dalam perhitungan logika Fuzzy Mamdani dan Electre. Untuk menghitung data hasil pernyataan dari responden dapat digunakan rumus sebagai berikut:

$$
\text { Populasi: } \begin{aligned}
\frac{\text { Nilai total responden }}{\text { Jumlah sub indikator }} & \\
& =\text { Nilai Pertanyaan }
\end{aligned}
$$

Fungsi Keanggotaan Variabel Waktu

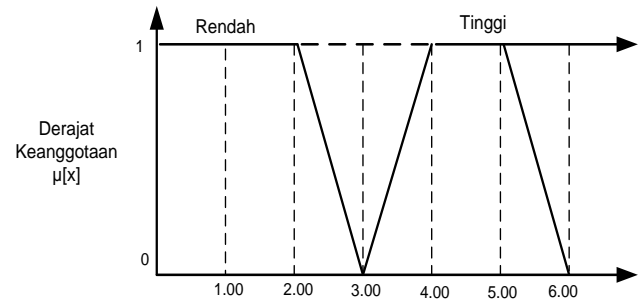

Gambar 4.1. Fungsi Keanggotaan

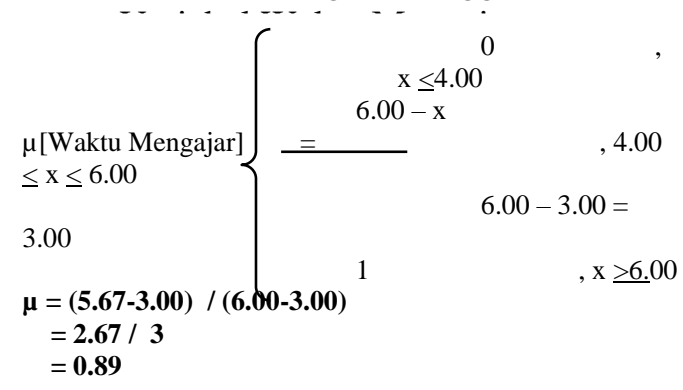

Hasil pembentukan rule sebagai berikut:

Hasil Komposisi Aturan

Setelah dilakukan penerapan fungsi implikasi dari setiap aturan, selanjutnya digunakan fungsi Min-
Max dari nilai rendah dan tinggi pada suatu derajat keanggotaan untuk melakukan komposisi antara semua aturan.

$$
\begin{aligned}
& a_{1} \quad-4.00 \\
& -----\quad=5.1 \ldots \ldots \ldots . . \mathrm{R} 1 \\
& 3.00-4.00 \\
& a_{l}=5.1(4.00-3.00)=1 \\
& a_{l}=\mathbf{0 . 1 9 6}
\end{aligned}
$$

Penegasan (Defuzzyfication)

$$
\begin{aligned}
Z & =\frac{5.1 * 0.196}{5.1} \\
& =\frac{0.9996}{5.1}=\mathbf{0 . 1 9 6}
\end{aligned}
$$

Hasil Pembuatan Kriteria Electre

Tabel 4.1. Variabel Penilaian

\begin{tabular}{|c|c|l|c|c|}
\hline No & Tanda & \multicolumn{1}{|c|}{ Nama Variabel } & Persentase & Pembobotan \\
\hline 1 & C1 & Waktu Mengajar & $15 \%$ & 0,15 \\
\hline 2 & C2 & Kerapihan Berpakaian & $20 \%$ & 0,20 \\
\hline 3 & C 3 & Komunikasi & $15 \%$ & 0,15 \\
\hline 4 & C4 & Proses Perkuliahan & $20 \%$ & 0,20 \\
\hline 5 & C 5 & Penguasaan Materi & $15 \%$ & 0,15 \\
\hline 6 & C6 & Evaluasi Belajar & $15 \%$ & 0,15 \\
\hline
\end{tabular}

Normalisasi Matrik Keputusan

Matriks keputusan yang dbentuk dari tabel kecocokan diatas adalah sebagai berikut :

Matriks $X=\begin{gathered}X_{11} \\ X_{21} \\ \cdot \\ \cdot \\ \cdot \\ X_{m 1}\end{gathered}\left\{\begin{array}{ccc}X_{12} \ldots \ldots \ldots & X_{1 n} \\ X_{22} \ldots \ldots . . & X_{2 n} \\ \cdot & & \cdot \\ \cdot & & \cdot \\ \cdot & & \cdot \\ X_{m 2} \ldots \ldots & X_{m n}\end{array}\right\}$

\section{Analisis Perbandingan Dengan Metode MSE (Mean Squared Error)}

MSE dalam hal ini menggunakan nilai akhir dari perhitungan antara kedua 
metode yaitu Fuzzy Mamdani dan Electre kemudian dikuadratkan. Berikut ini rumus yang digunakan :

$$
\mathrm{MSE}=\frac{\sum_{t=1}^{n}\left(A_{t}-F_{t}\right)^{2}}{n}
$$

\section{PENUTUP}

\section{Kesimpulan}

Berdasarkan uraian diatas, kesimpulan dari penelitian ini adalah dengan menggunakan menggunakan metode fuzzy mamdani dan electre dapat dihasilkan:

1. Penerapan logika fuzzy Mamdani dan ELECTRE menghasilkan alternative keputusan yang berbeda jika menggunakan fuzzy mamdani nilai tertinggi diperoleh alternatif A6 atas nama SUSILAWATI,SH.,S.Pd.,M.Pd dengan nilai akurasi 0,196. Sedangkan jika menggunakan metode electre maka diperoleh alternative A6 juga atas nama

\section{SUSILAWATI,SH.,S.Pd.,M.Pd} dengan total nilai preferensi sebanyak 2.

2. Dari ke dua metode yang digunakan masing-masing memiliki tingkat kesulitan dalam perhitungan dengan metode electre dapat disimpulkan bahwa dosen yang memiliki total nilai kuesionaer belum tentu menjadi yang tertinggi nilai preferensinya. Sedangkan dengan menggunakan metode fuzzy mamdani disimpulkan bahwa dosen yang memiliki nilai total besar pada kuesioner akan menjadi nilai preferensi tertinggi.

\section{Saran}

Berdasarkan kesimpulan diatas
maka penulis ingin memberikan saran
antara lain:
1. Dengan perbedaan hasil yang diperoleh dari perhitungan ke dua metode diatas, tidak akan menjadi masalah dalam pengambilan keputusan karena kedua metode memiliki cara perhitungan yang sangat akurat dan terinci.

2. Akan lebih baik jika dosen lebih memperhatikan dari setiap kriteria yang dibebankan ke dosen sehingga dapat melakukan tanggung jawab dengan baik.

\section{DAFTAR PUSTAKA}

[1] Andayati, Dina. 2010. Sistem Pendukung Keputusan Pra-Seleksi Penerimaan SiswaBaru (Psb) On-Line Yogyakarta. Institut Sains dan Teknologi AKPRIND. Yogyakarta

[2] Ariani, Pepi Dwi. 2010. Sistem Pendukung Keputusan Pemilihan Jurusan Smk Menggunakan NeuroFuzzy. Institute Teknologi Sepuluh Nopember. Surabaya

[3] Kusumadewi, S, and Purnomo, H, 2010, Aplikasi Logika Fuzzy Untuk Pendukung Keputusan, GrahaIlmu.Yogyakarta.

[4] Kusumadewi, S, 2005. Fuzzy Quantification Theory I Untuk Analisis Hubungan Antara penilaian Kinerja DosenOleh Mahasiswa, Kehadiran Dosen dan Nilai Kelulusan Mahasiswa, Media Informatika, Volume 2. No 1.

[5] Margi, Kristien. 2015. Analisa dan Penerapan Metode Single Exponential Smoothing Untuk Prediksi Penjualan Pada Periode Tertentu. Fakultas Teknologi dan Desain Universitas Bunda Mulia. Jakarta

[6] Muntaha, Muthia Sidratull. 2011. Penerapan Sistem Pendukung Keputusan Untuk Menyeleksi Calon

Aisyah Journal of Informatics and Electrical Engineering 
Siswa Smk Berdasarkan Hasil Test Menggunakan Metode Fuzzy Di Smk Teratai Putih Global 1 Bekasi. Universitas Komputer Indonesia. Bandung

[7] Pratiwi, Dr.Heny. 2016. Sistem Pendukung Keputusan. Deeppublish. Yogyakarta

[8] P. R. Indonesia, Undang - Undang Republik Indonesia Nomor 20 Tahun 2003 tentang Sistem Pendidikan Nasional, Jakarta: Sekretaris Negara Republik Indonesia, 2003.

[9] P. R. Indonesia, Peraturan Pemerintah Republik Indonesia Nomor 37 Tahun 2009 tentang Dosen, Jakarta: Sekretariat Negara Republik Indonesia, 2009.

[10] Rohmat Taufiq. 2015. Penilaian kinerja dosen dalam bidang belajar mengajar di fakultas teknik universitas muhammadiyah tanggerang, Faktor Excata Vol. 5 No. 1:77-85. Universitas Muhamadiyah Tangerang. ISSN: 1979 276X.
[11] Roy. B. 1973. "How Outranking Relation Helps Multiple Criteria Decision Making", dalam: Janko, Wolfgang. 2005. Multi-criteria decision making: An aplication study of ELECTRE \& TOPSIS.

[12] Suharsimi. 2008, Dasar-Dasar Statistika, Bandung: Alfabeta

[13] Sujarweni, V.Wiratna. 2014. Metodologi Penelitian. Penerbit Pustakabarupress. Yogyakarta

[14] Syeril Akshareari. 2013, Sistem Pendukung Keputusan Pemilihan Produksi Sepatu Dengan Metode Elimination and Choice Expressing Reality (ELECTRE). Perpustakaan.upi.edu. Universitas Pendidikan Indonesia.

[15] T.Sutojo. 2005. Kecerdasan Buatan /Logika Fuzzy. Penerbit Andi. Yogyakarta 